Short communication

\title{
In-situ gelled electrolyte for lithium battery: Electrochemical and Raman characterization
}

\author{
Lucia Lombardo a , Maria Assunta Navarra ${ }^{a}$, Stefania Panero ${ }^{a}$, Luis Aguilera Medina ${ }^{b}$, \\ Aleksandar Matic ${ }^{\mathrm{b}}$, Jusef Hassoun ${ }^{\mathrm{a}, *}$ \\ a Department of Chemistry, Sapienza University of Rome, 00185 Rome, Italy \\ ${ }^{\mathrm{b}}$ Department of Applied Physics, Chalmers University of Technology, S41296 Göteborg, Sweden
}

\section{H I G H L I G H T S}

- Polymer lithium cell using a PVdF-based, gel-type electrolyte is reported.

- The gel electrolyte is formed in-situ during cell assembly.

- Electrochemical impedance and Raman spectroscopy are used for electrolyte study.

- The polymer lithium cell is prepared using $\mathrm{LiNi}_{0.5} \mathrm{Mn}_{1.5} \mathrm{O}_{4}$, spinel-type cathode.

- The cell is characterized by high voltage, good stability and high safety content.

\section{A R T I C L E I N F O}

\section{Article history:}

Received 22 January 2013

Received in revised form

12 June 2013

Accepted 14 June 2013

Available online 25 June 2013

\section{Keywords:}

Polymer-cell

Gel-electrolyte

In-situ

Raman

EIS

$\mathrm{LiNi}_{0.5} \mathrm{Mn}_{1.5} \mathrm{O}_{4}$

\begin{abstract}
A B S T R A C T
In this paper we report a polymer lithium cell using a PVdF-based, gel-type electrolyte formed in-situ during cell assembly. The gel electrolyte formation is monitored prior to cell assembly by electrochemical impedance spectroscopy and by Raman spectroscopy in order to determine the characteristics of the lithium salt diffusion into the gel-membrane. The results show an efficient gel formation and a fast lithium salt diffusion, this finally resulting in an optimized behaviour in a lithium cell using a high voltage spinel-type cathode. We believe that the results here reported may contribute to the enhancement of the safety of lithium batteries.
\end{abstract}

(C) 2013 Elsevier B.V. All rights reserved.

\section{Introduction}

Lithium ion batteries are now triggering great attention since they are considered the most suitable power source for electric and hybrid vehicles [1]. However, the safety issues associated with the presence of organic, flammable solvents as the electrolyte are still preventing a large diffusion of the technology in these emerging markets [2]. Solid polymer electrolytes, such as polyethylene oxide (PEO), are considered the best choice to overcome the safety hazards, however problems associated with their low conductivity at

\footnotetext{
* Corresponding author.

E-mail address: jusef.hassoun@uniroma1.it (J. Hassoun).
}

lower temperature still need to be addressed [3]. A very promising alternative was represented by the gelified systems, such as those based on poly(vinylidene)fluoride (PVdF), consisting of a polymer membrane acting as matrix for the organic liquid part, generally organic carbonates [4]. This solution was considered as a compromise between safety and performances in terms of ionic conductivity and rate capability when employed in lithium cells [5].

Different approaches have been taken in the past to prepare PVdF gel-type conducting membranes, such as those based on casting procedures [6] or on electro-spinning [7]. For both methods a swelling step is necessary to introduce a lithium salt into the membrane. However, these approaches revealed several issues associated with cell assembly and scaling up due to the poor mechanical stability of the gel membranes, in particular in roll-to-roll 
Table 1

Conditions used for the preparation of the gel electrolyte.

\begin{tabular}{lll}
\hline & Temperature, ${ }^{\circ} \mathrm{C}$ & Time \\
\hline Mixing & Room temperature & $2 \mathrm{~h}$ \\
Pre-heating & 70 & $15 \mathrm{~min}$ \\
Casting & 70 & $20 \mathrm{~min}$ \\
Quenching & Room temperature & $20 \mathrm{~min}$ \\
\hline
\end{tabular}

systems, commonly used for cell prototype preparation. To overcome this issue, in this paper we report an alternative preparation approach consisting of an "in-situ" formation of the gel matrix during lithium-metal cell assembly, followed by the lithium salt infiltration step. The lithium salt diffusion into the gel is investigated by electrochemical impedance spectroscopy (EIS) and by Raman spectroscopy. The results demonstrated an efficient gel formation and a fast salt infiltration that allowed the use of the membrane in a lithium cell using a spinel-structure, $\mathrm{LiNi}_{0.5} \mathrm{Mn}_{1.5} \mathrm{O}_{4}$ high voltage cathode. It is expected that the procedure reported here may lead to the in-situ gel preparation also in full cell systems, combining both lithium ion cathode and anode, with the aim to increase the cell safety. In addition, the in-situ gelation procedure proposed may be successfully extended to a large variety of different applications, mainly to solve problems related to possible leakage of active components or analytical species. For example, drawbacks in the instrumental setup of some particular analyses, such as those based on in-situ spectroscopy or X-ray diffraction techniques, could be overcome by adopting a gelled configuration, to be easily realized in-situ, in order to avoid the presence of free liquids.

\section{Experimental}

\subsection{Gel polymer electrolyte preparation and characterization}

A membrane having the desired composition was prepared exsitu by adapting a solvent casting procedure already developed in our laboratories [4]. The preparation of this membrane was aimed to fully investigate its characteristics prior to in-situ gel formation. Two low molecular weight aprotic solvents, ethylene carbonate (EC, Merck battery grade, 99.9\%) and dimethyl carbonate (DMC, Merck battery grade, $99.9 \%$ ) in a weight ratio of $1: 1$, were mixed with poly(vinylidene)fluoride (PVdF Solvay Solef ${ }^{\circledR}$ 6020). Details on the preparation procedure of the gel polymer membrane are reported in Table 1. The final composition of the membrane was: EC:DMC/ PVdF 80/20 wt/wt.

The as-prepared gel polymer membrane having a thickness of about $500 \mu \mathrm{m}$ was held in a Swagelok, stainless steel electrode Tcell with geometric surface area of $0.785 \mathrm{~cm}^{2}$ and infiltrated with the Li-salt from a solution of $1 \mathrm{M}$ lithium hexafluorophosphate $\left(\mathrm{LiPF}_{6}\right)$ in EC:DMC 1:1 wt/wt, (LP30, Merck) for various time regimes at room temperature. This approach was adopted to preliminarily verify the applicability of in-situ activation and gel polymer electrolyte formation.

The ionic conductivity of the membrane during $\mathrm{LiPF}_{6}$ infiltration was monitored by AC impedance (cell constant calculated to be $0.065 \mathrm{~cm}^{-1}$ in the configuration adopted). The impedance measurements were performed applying a $10 \mathrm{mV}$ amplitude signal in the $100 \mathrm{kHz}-100 \mathrm{~Hz}$ frequency range using a frequency response analyzer (FRA) Schlumberger Solartron model 1260.

The effective occurrence of $\mathrm{LiPF}_{6}$ infiltration was also monitored by Raman spectroscopy, which allowed the determination of the lithium salt content. The analysis was performed in a sealed glass cuvette containing a LP30:gel membrane $2: 1 \mathrm{v}: \mathrm{v}$ ratio. The dimensions of the cuvette were: height $45 \mathrm{~mm}$, width $12.5 \mathrm{~mm}$, depth $12.5 \mathrm{~mm}$, inner width $2 \mathrm{~mm}$, volume $700 \mu$ l. The Raman characterization was carried out on a Bruker MultiRAM FT-Raman spectrometer using a diode-pumped Nd:YAG laser with a wavelength of $1064 \mathrm{~nm}$ and a liquid nitrogen cooled Ge diode detector. The laser power was set to $400 \mathrm{~mW}$ and data were collected in 5 min intervals. The spectra have been deconvoluted by fitting with three Voigt functions according to the experimental profile reported in the result and discussion part of the manuscript.

\subsection{In-situ gel formation in the lithium cell}

The membrane described previously (see Table 1 ) was prepared in-situ in a Swagelok, stainless steel electrode T-cell with geometric surface area of $0.785 \mathrm{~cm}^{2}$ coupling lithium metal (Li-foil, $38 \mu \mathrm{m}$ thick, Chemetall) and a $\mathrm{LiNi}_{0.5} \mathrm{Mn}_{1.5} \mathrm{O}_{4}$ cathode prepared in our laboratory as reported in previous papers [8], using a glass fibre separator (type/A, Whatman ${ }^{\circledR}$ ) to avoid short circuit, and a lithium metal anode. The in-situ gelification was performed by introducing the polymer solution (EC:DMC $1: 1 / \mathrm{PVdF}, 80 / 20 \mathrm{wt}$ ) heated at $70^{\circ} \mathrm{C}$ into the cell held at the same temperature, followed by a quench to room temperature. Subsequently, the $\mathrm{LiPF}_{6}$ infiltration was
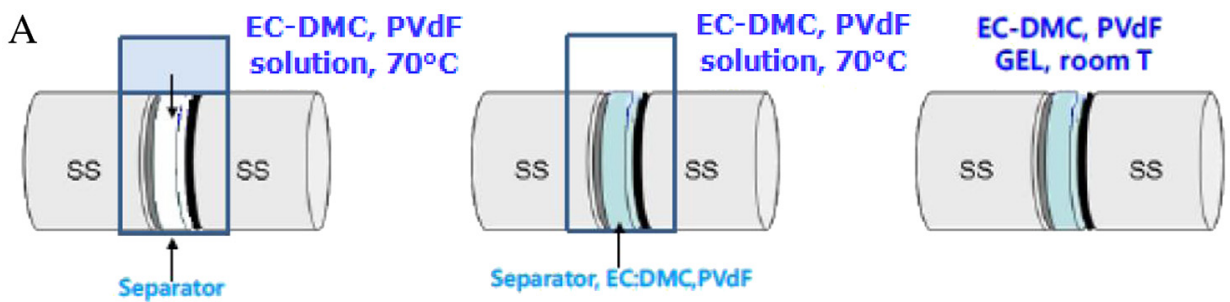

B
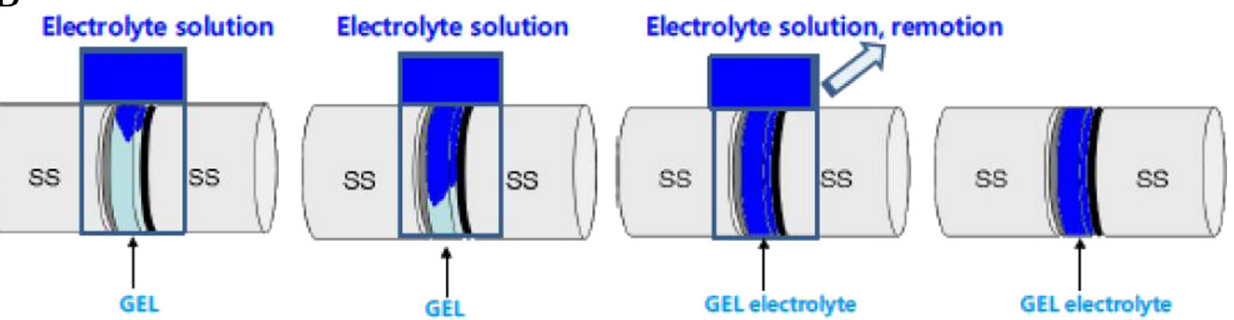

Scheme 1. Schematic representation of the in situ EC-DMC-PVdF gel formation (A) and LiPF 6 salt infiltration in the gel membrane (B). 
performed by direct contacting the in-situ formed gel with LP30 (i.e., EC:DMC 1:1, LiPF $1 \mathrm{M}$ ) for $300 \mathrm{~min}$. The LP30 solution was added in a 2:1 $v: v$ ratio, in order to get a final concentration of the salt in the gel electrolyte approaching $0.5 \mathrm{M}$, and completely removed from the cell after $3 \mathrm{~h}$, after completion of $\mathrm{LiPF}_{6}$ salt infiltration (see Scheme 1). The use of the $\mathrm{LiPF}_{6}$ was avoided during the gelation procedure, this in order to prevent eventual reactions with the solvents upon heating.

Relevant DMC evaporation was not observed during the gel preparation, since the liquid precursors have been heated in a sealed bottle. However, a minor evaporation during the fast insertion of the liquid precursors into the cell before sealing, cooling and consequent gelation cannot be excluded.

The cell was galvanostatically cycled at room temperature using a C/5 rate (of about $0.15 \mathrm{~mA} \mathrm{~cm}{ }^{-2}$, with $1 \mathrm{C}$ current being $148 \mathrm{~mA} \mathrm{~g}{ }^{-1}$ with respect to $\mathrm{LiNi}_{0.5} \mathrm{Mn}_{1.5} \mathrm{O}_{4}$ active mass having a loading of about $5 \mathrm{mg} \mathrm{cm}^{-2}$ ), within the voltage range $3.5-5.0 \mathrm{~V}$ employing a Maccor Series 4000 Battery Test System. The performance of the cell was evaluated in terms of specific capacity and cycle life.

\section{Results and discussion}

The procedure here reported for the gel-type electrolyte in-situ preparation involved two different steps: the gel membrane
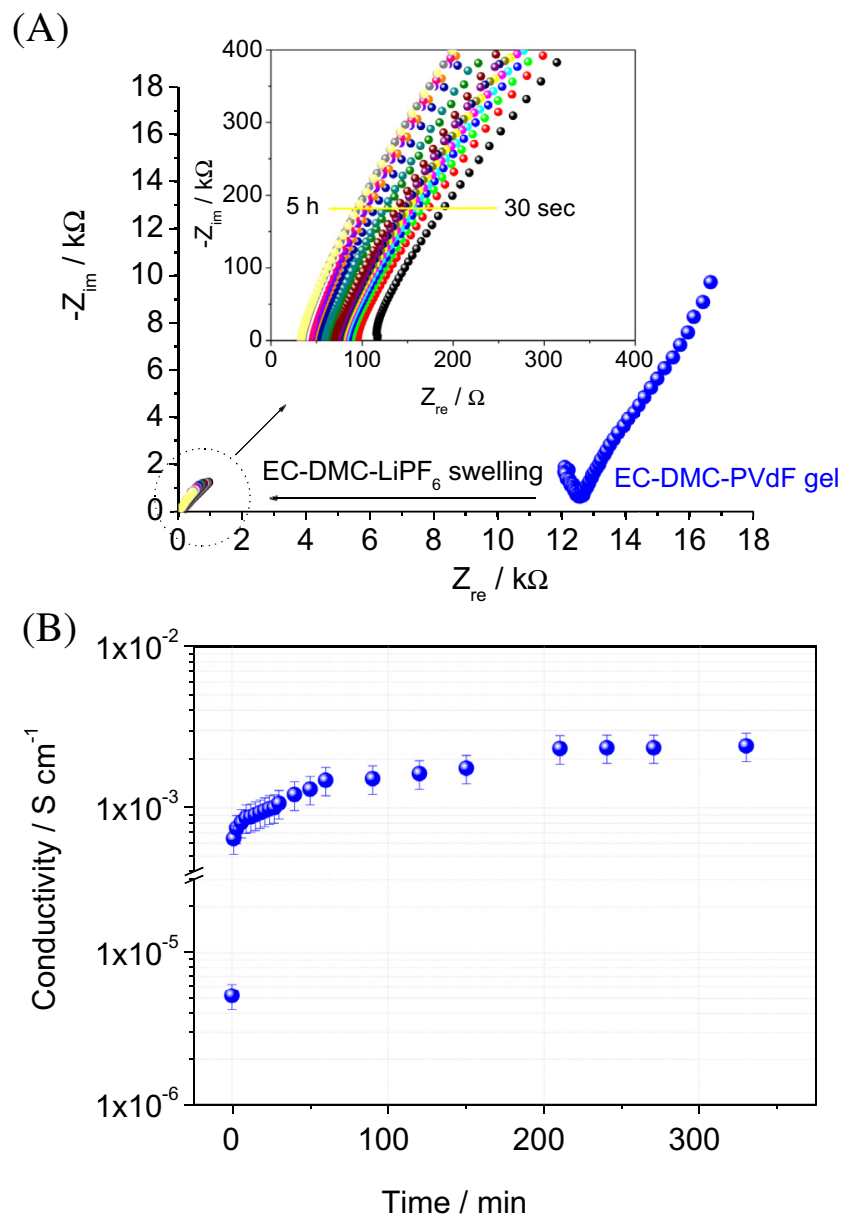

Fig. 1. Time evolution of the Nyquist impedance plots $(A)$ and of the corresponding conductivity values (B) during PVdF-based gel infiltration by the $\mathrm{LiPF}_{6}$ salt dissolved in a EC:DMC 1:1 solvent. $100 \mathrm{kHz}-100 \mathrm{~Hz}$ frequency range, r.t. formation and the lithium salt, i.e. $\mathrm{LiPF}_{6}$, infiltration. The two-step procedure has been designed in order to avoid side reactions of $\mathrm{LiPF}_{6}$ with the solvent, or the other cell materials, during the gel preparation, in particular considering that the process involves heating. In fact, fluorinated radicals may be generated by heating solutions containing $\mathrm{LiPF}_{6}$ salt that may react with the hydrocarbons, this producing several fluorinated species, among them the $\mathrm{HF}$, i.e. "very reactive specie" leading to severe cell degradation.

Prior to in-situ formation and use of the gel electrolyte in the lithium cell, we studied the behaviour of the membrane in terms of $\mathrm{LiPF}_{6}$ salt infiltration "see also Experimental section". Fig. 1 reports the Nyquist impedance plots (A) and the corresponding time evolution of the conductivity (B) during infiltration, clearly showing an initial, fast increase of the electrolyte conductivity from a value of about $4 \times 10^{-6} \mathrm{~S} \mathrm{~cm}^{-1}-4 \times 10^{-4} \mathrm{~S} \mathrm{~cm}^{-1}$ in the first few minutes, followed by a slower increase and stabilization to a value of about $3 \times 10^{-3} \mathrm{~S} \mathrm{~cm}^{-1}$. This behaviour proves that the lithium salt diffusion into the polymer matrix is fast.

(A)
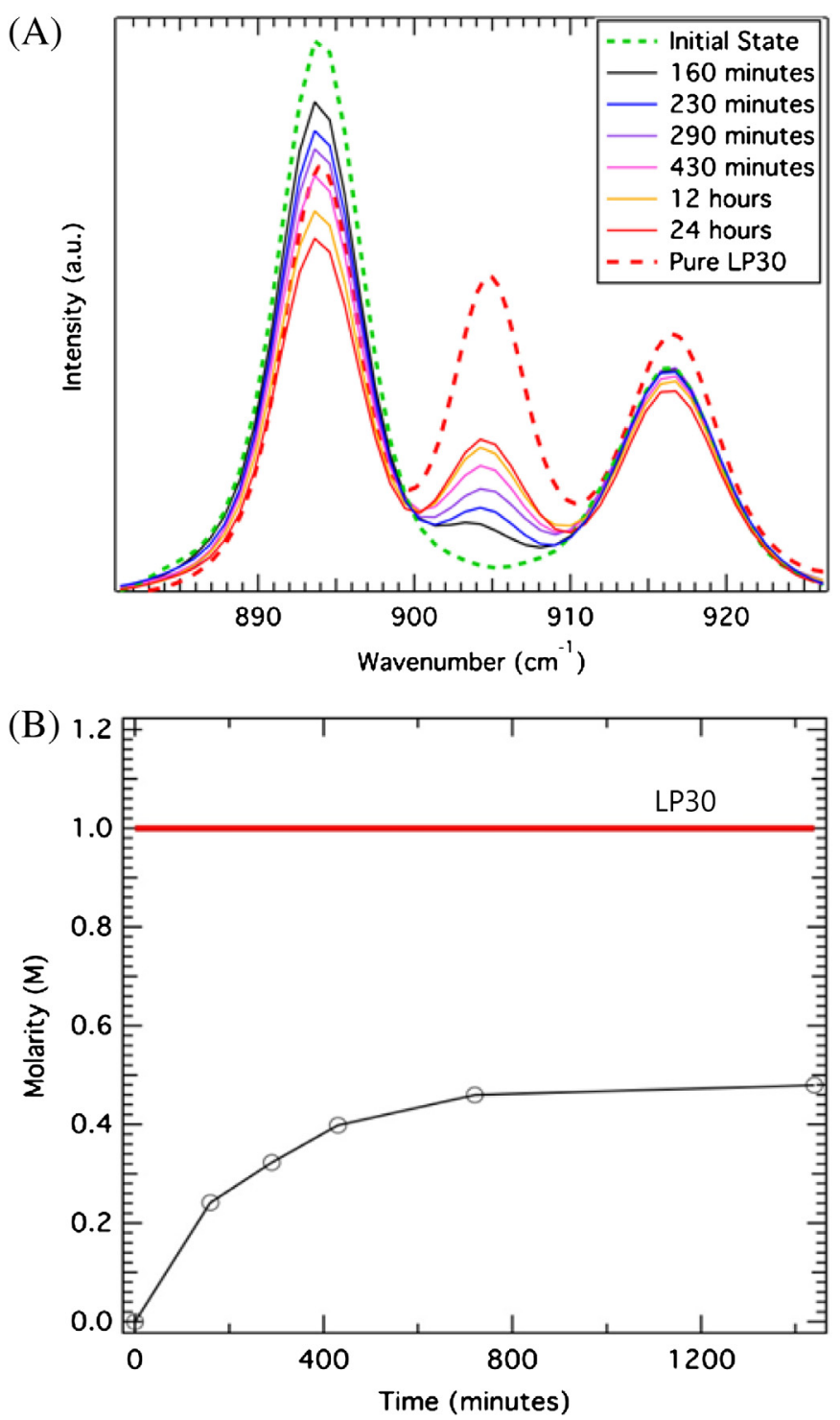

Fig. 2. Time evolution of the FT-Raman spectra (A) and corresponding variation of the diffused salt amount (B) during PVdF-based gel infiltration by the $\mathrm{LiPF}_{6}$ dissolved in a EC:DMC 1:1 solvent at r.t. The molar concentration vs. time graph (B) was obtained by integrating the $905 \mathrm{~cm}^{-1}$ band. 
Similar behaviour is observed by the FT-Raman analysis reported in Fig. 2. The spectral range of $880-930 \mathrm{~cm}^{-1}$ had previously been used to study the solvatation of Li by EC molecules $\left(905 \mathrm{~cm}^{-1}\right)$ as a function of Lithium salt concentration [9]. A similar feature can be found for the DMC molecules at slightly higher wave numbers (about $934 \mathrm{~cm}^{-1}$ ), which was however neglected for the calculation due to its low intensity and short acquisition times. Furthermore, the absence of Raman active modes of the PVdF within the studied range excluded eventual background subtraction. Two characteristic peaks, at 894 and $917 \mathrm{~cm}^{-1}$ corresponding to the ring breathing mode of EC [10] and to the $\mathrm{C}-\mathrm{O}$ stretching mode of DMC [11], respectively, are observed for the gel-cast sample in its pristine state. As the Lithium salt diffuses into the gel-cast membrane, the characteristic feature of EC solvating Li-ions at $905 \mathrm{~cm}^{-1}$ appears [12] and its intensity increases upon time, as can be seen from the Raman spectra in Fig. 2A. The integrated area of this peak (see Experimental section) can be directly related to the lithium concentration (molar) in the gel membranes (Fig. 2B), which follows a similar trend to that observed in the conductivity plot, see Fig. 1B. For comparison, Fig. $2 \mathrm{~A}$ reports the spectrum of the neat liquid electrolyte EC:DMC, $\mathrm{LiPF}_{6}$ (LP30). One should notice that the liquid component in the final gel polymer electrolyte has a lithium salt concentration of the order of half of that of LP30. This is also reflected in an expected lower ionic conductivity, i.e. of the order of $3 \times 10^{-3} \mathrm{~S} \mathrm{~cm}^{-1}$ vs. $1 \times 10^{-2} \mathrm{~S} \mathrm{~cm}^{-1}$ at room temperature, respectively, that is still well within the lithium battery application requirements [13].

Fig. 3 shows the voltage profile (A) and the cycling behaviour (B) of the lithium cell using a high voltage $\mathrm{LiNi}_{0.5} \mathrm{Mn}_{1.5} \mathrm{O}_{4}$ spinel

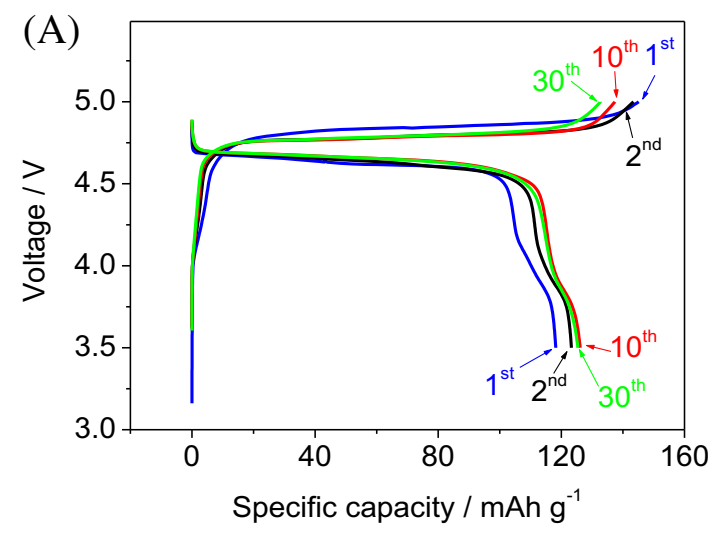

(B)

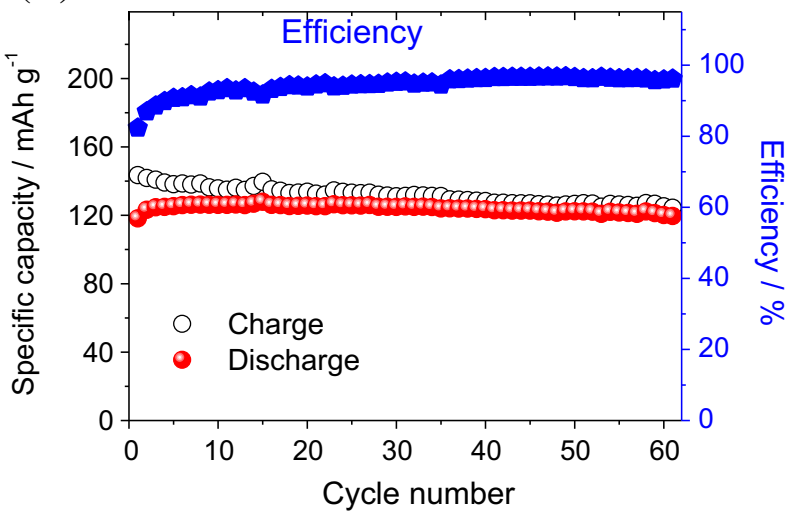

Fig. 3. Voltage profile (A) and the cycling behaviour (B) of the Li/PVdF-EC:DMC-LiPF 6 / $\mathrm{LiNi}_{0.5} \mathrm{Mn}_{1.5} \mathrm{O}_{4}$ cell in which the gel-type electrolyte was prepared in-situ as described in the paper. cathode having a theoretical capacity of $148 \mathrm{mAh} \mathrm{g}^{-1}$ and the insitu prepared polymer gel-type electrolyte, with the expected voltage signature of the $\mathrm{LiNi}_{0.5} \mathrm{Mn}_{1.5} \mathrm{O}_{4}$ cathode [14] characterized by the following reaction mechanism:

$\mathrm{LiNi}_{0.5} \mathrm{Mn}_{1.5} \mathrm{O}_{4} \leftrightarrow \mathrm{Li}_{1-\chi} \mathrm{Ni}_{0.5} \mathrm{Mn}_{1.5} \mathrm{O}_{4}+x \mathrm{Li}^{+}+x \mathrm{e}^{-}$

The cell displays a reversible capacity of $120 \mathrm{mAh} \mathrm{g}^{-1}$, with relatively low efficiency, i.e. of the order of $85 \%$, during the initial 10 cycles. This is most likely due to SEI film formation at the electrode surface [15] with electrolyte decomposition at the high voltage of $5 \mathrm{~V}$ at the cathode side and structural readjustment upon initial lithium uptake/removal, typical of lithium-ion electrochemical processes [16]. During the following cycles the stabilization of the SEI layer prevents further decomposition and the cell efficiency values increases to about $97 \%$, with remarkable reversibility during operation and high capacity retention. This demonstrated the applicability of the in-situ gelification method reported in this work.

\section{Conclusion}

In this paper we reported on an alternative approach for preparation of a Li-battery cell with the in-situ formation of a gel-type electrolyte as an innovative step. The electrolyte, characterized by electrochemical techniques and Raman spectroscopy, demonstrates an appropriate behaviour in terms of ionic conductivity and cell performance in a lithium battery using a high voltage spineltype cathode. We believe that the approach adopted in this work may be successfully applied in lithium batteries, and that, upon proper optimization in terms of liquid-salt-polymer relative amount, the in-situ gelification can be proposed for a larger-scale process, in particular if recycling conditions are adopted. Further attempts, aimed at a full understanding of the physical phenomena involved in the in-situ gelation process here described will be reported in future papers, together with the electrochemical characterization of different Li-ion cell configurations adopting in-situ gelled polymer electrolytes.

\section{Acknowledgements}

The results of this work have been obtained thanks to the financial support of the European Community within the Seventh Framework Programme APPLES (Advanced, High Performance, Polymer Lithium Batteries for Electrochemical Storage) Project (contract number 265644).

\section{References}

[1] J.M. Tarascon, M. Armand, Nature 414 (2001) 359.

[2] K. Xu, Chem. Rev. 104 (2004) 4303.

[3] F. Croce, G.B. Appetecchi, L. Persi, B. Scrosati, Nature 394 (1998) 456

[4] G.B. Appetecchi, P. Romagnoli, B. Scrosati, Electrochem. Commun. 3 (2001) 281.

[5] J. Hassoun, S. Panero, P. Reale, B. Scrosati, Adv. Mater. 2 (2009) 4807.

[6] J. Hassoun, P. Reale, Bruno Scrosati, J. Mater. Chem. 17 (2007) 3668.

[7] F. Croce, M.L. Focarete, J. Hassoun, I. Meschinia, B. Scrosati, Energy Environ. Sci. 4 (2011) 921.

[8] P. Reale, S. Panero, B. Scrosati, J. Electrochem. Soc. 152 (2005) A1949.

[9] S. Hyodo, K. Okabayashi, Electrochim. Acta 34 (1989) 1551.

[10] F.B.P. Mirone, G. Fini, Spectrochim. Acta Part A A 27 (1971) 1917.

[11] J.E. Katon, M.D. Cohen, Can. J. Chem. 53 (1975) 1378.

[12] M. Morita, Y. Asai, N. Yoshimoto, M. Ishikawa, J. Chem. Soc. Faraday Trans. 94 (1998) 3451.

[13] B. Scrosati, J. Garche, J. Power Sources 195 (2010) 2419.

[14] D. Aurbach, J. Power Sources 89 (2000) 206.

[15] R.A. Huggins, J. Power Sources 81 (1999) 13.

[16] J.C. Arrebola, A. Caballero, L. Hernán, J. Morales, Electrochem. Solid-State Lett. 152 (2005) 641. 